\title{
Erratum to: $N$-Terminal seven-amino-acid extension simultaneously improves the pH stability, optimal temperature, thermostability and catalytic efficiency of chitosanase CsnA
}

Yujuan Han $\cdot$ Peixin Gao $\cdot$ Wengong Yu $\cdot$ Xinzhi Lu

Published online: 5 December 2017

(C) Springer Science+Business Media B.V. 2017

Erratum to: Biotechnol Lett

DOI 10.1007/s10529-017-2436-9

In Table 1 as published, some of the data were wrong.

The corrected Table 1 is shown here.

Table 1 Kinetic parameters and specific activities of CsnA and $\operatorname{Csn} A \Delta N$

\begin{tabular}{llllll}
\hline Enzyme & $K_{m}(\mathrm{~g} / \mathrm{l})$ & $V_{\max }(\mu \mathrm{M} / \mathrm{s})$ & $k_{\text {cat }}\left(\mathrm{s}^{-1}\right)$ & $k_{\text {cal }} / K_{m}(\mathrm{l} / \mathrm{g} / \mathrm{s})$ & Specific activity $(\mathrm{U} / \mathrm{mg})^{\mathrm{a}}$ \\
\hline CsnA & $2.8 \pm 0.32$ & $0.27 \pm 0.02$ & $25 \pm 2$ & 8.9 & $3.4 \times 10^{2} \pm 15$ \\
CsnA $\Delta \mathrm{N}$ & $2.6 \pm 0.3$ & $0.25 \pm 0.01$ & $20 \pm 0.58$ & 7.7 & $2.6 \times 10^{2} \pm 19$
\end{tabular}

${ }^{\text {a}}$ Values are means \pm SD

The online version of the original article can be found under doi:10.1007/s10529-017-2436-9.

Y. Han · P. Gao · W. Yu · X. Lu ( ()

Key Laboratory of Glycoscience \& Glycotechnology of Shandong Province; Key Laboratory of Marine Drugs, Chinese Ministry of Education; Laboratory for Marine Drugs and Bioproducts, Qingdao National Laboratory for Marine Science and Technology; Department of Glycobiology; School of Medicine and Pharmacy, Ocean University of China, 5 Yushan Road, Qingdao 266003, China

e-mail: luxinzhi@ouc.edu.cn 